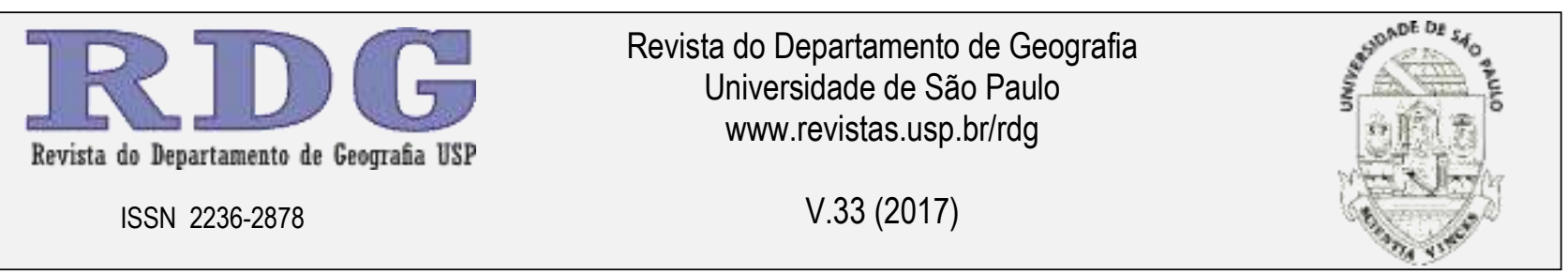

\title{
Dinâmica de Inundação do Banhado a partir do Índice NDPI, Reserva Biológica de São Donato - RS
}

\author{
Marsh Flood Dynamics from the NDPI Index, \\ Biological Reserve of São Donato - RS
}

\author{
Daniela Zanetti Bittencourt \\ Universidade Federal do Rio Grande do Sul \\ daniza.bittencourt@gmail.com \\ Laurindo Antonio Guasselli \\ Universidade Federal do Rio Grande do Sul \\ laurindo.guasselli@ufrgs.br
}

Recebido (Received): 27/01/2017 DOI: $10.11606 /$ rdg.v33i0.125834

\begin{abstract}
Resumo: Os banhados característicos do bioma Pampa fazem parte de um grande leque de áreas úmidas, que são periodicamente inundadas por reflexo lateral de rios e de lagos, pela precipitação direta ou por água subterrânea. Para compreender a dinâmica desses ambientes - em especial o banhado da Reserva Biológica de São Donato $\mathrm{RS}$, a partir de processamento de imagens Landsat 5 e Landsat 8, foi utilizado o índice NDPI (Normalized Difference Pond Index ou Índice de Diferença Normalizada de Corpos de água) e registros de precipitação diários e mensais de quatro estações pluviométricas, duas locais e duas montantes do rio Uruguai. Foram determinadas classes de NDPI: Muito Seco, Seco, Úmido e Muito Úmido. Os resultados mostram que existem padrões nas imagens NDPI associados as manchas de inundação. Foram definidos três padrões de inundação no banhado da reserva: o regional, por influência de chuvas oriundas do trecho a montante na bacia do rio Uruguai; o sub-regional, por influência de chuvas oriundas ao leste, da sub-região hidrográfica dos rios Butuí e Icamaquã; e um padrão local, por influência de chuvas à montante do rio Butuí, que afeta o banhado com o encharcando do solo.
\end{abstract}

Palavras-Chave: Área Úmida; Índices de Umidade; Planícies Inundáveis; Padrões de Inundação.

\begin{abstract}
The characteristic marshes of the Pampa biome are part of a wide range of wetlands, which are periodically flooded by lateral reflections of rivers and lakes, by direct precipitation or by groundwater. In order to understand the dynamics of these environments - in particular the marsh of the São Donato Biological Reserve - RS, from the Landsat 5 and Landsat 8 images processing, the Normalized Difference Pond Index (NDPI) index and daily and monthly precipitation records of two rain stations were used, one local and the other upstream of the Uruguay River. The results show that there are patterns in the NDPI images from the flood spots. NDPI classes were determined: Very Dry, Dry, Moist and Very Moist. Three flood patterns were defined in the reserve marsh, observed through the NDPI images: the regional one, due to the influence of rains originating from areas north of the marsh, in the upstream stretch; The sub-regional, due to the influence of rainfall in the east, of the hydrographic sub-region of the rivers Butuí and Icamaquã; And a local pattern, influenced by rainfall upstream of the Butuí River, which directly affects the marsh with soaking the soil.
\end{abstract}

Keywords: Wetland; Humidity Index; Flood Plains; Flood Patterns. 


\section{INTRODUÇÃO}

A utilização de índices de vegetação (IV) constitui uma importante estratégia para o monitoramento das alterações naturais, ou produzidas pelo homem, nos ecossistemas (FEITOSA et al., 2006). Entretanto, a maioria dos modelos de IV foram desenvolvidos com o objetivo de estudar o estado de vigor da vegetação, com base na presença de pigmentos que participam dos processos fotossintéticos, em particular ao conteúdo de clorofila (GITELSON et al., 1996; PONZONI et al., 2012; RISSO et al., 2012).

No caso de Áreas Úmidas (AU) é necessário conhecer a sua dinâmica de inundação com relação à vegetação e ao solo, sendo possível uma análise da resposta da influência da água, gerada por diferentes índices, nesses alvos de interesse, como o NDWI (Normalized Difference Water Index), o MNDWI (Modified Normalized Difference Water Index) e o NDPI (Normalized Difference Pond Index).

O NDWI tem sido mais utilizado em áreas úmidas como planícies inundáveis (BRUBACHER e GUASSELLI, 2013; BORGES et al., 2015; BRENNER, 2016); o MNDWI para identificação de corpos de água e áreas úmidas (WANG et al., 2013; Saavedra et al., 2015); e o NDPI para delinear limites e classificar áreas úmidas definindo seus principais compartimentos (JI et al., 2009; RAY et al., 2012; MOZUMDER et al., 2014; KUMAR, 2015).

De acordo com Ji et al. (2009) o uso do NDPI para áreas úmidas possui relação direta com bandas que proporcionam melhores valores de reflectância para alvos relacionados a vegetação que interagem com a água. Segundo Novo (2010) com relação à interação da água: a curva espectral da vegetação fotossinteticamente ativa, de acordo com as bandas correspondentes ao NDPI (bandas do infravermelho distante e do verde) são respectivamente ligados à absorção do conteúdo de água da folha e pela percepção dos pigmentos da folha.

Para Brinson (1993) Áreas Úmidas - do tipo banhados - são determinadas por sua hidrodinâmica, ou seja, refere-se ao movimento da água e a capacidade de transporte dos sedimentos e nutrientes para a superfície. Configurando-se em três categorias de hidrodinâmica: as flutuações; os fluxos unidirecionais; e os bidirecionais de superfície.

Inundação, conforme Kobyiama et al. (2006), se refere ao aumento do nível dos rios além da sua vazão normal, ocorrendo o transbordamento de suas águas sobre as áreas próximas a ele (planícies de inundação). Além disso, segundo Viana et al. (2010), com a presença de precipitação abundante por um período de tempo, o solo dessas áreas passa a ter sua capacidade de infiltrar reduzida ou, mesmo, suplantada, grande parte do volume escoa para o sistema de drenagem, que vê sua capacidade natural de escoamento saturada. O excesso de volume não-drenado ocupa a várzea, que é inundada de acordo com a topografia das áreas próximas aos rios.

Eventos de inundação na bacia hidrográfica do rio Uruguai são recorrentes. De acordo com Righi (2010) entre 1980 e 2005 foram registradas 41 ocorrências de inundação. Segundo Righi (2016) não há uma sazonalidade para essas ocorrências, devido ao clima subtropical que influencia a região da bacia; e de sua característica de chuvas distribuídas ao longo do ano. Assim, esse trabalho tem como objetivo compreender a dinâmica de inundações no banhado da Reserva Biológica (REBIO) de São Donato - RS, e de seu contexto hidrográfico, a partir de imagens do índice NDPI e dados de precipitação.

\section{2. ÁREA DE ESTUDO}

A área de estudo corresponde a sub-região hidrográfica dos rios Butuí-Icamaquã, sub-bacia do baixo trecho médio do rio Uruguai, Rio Grande do Sul (Figura 1). Segundo o Relatório do Diagnóstico da Região da Bacia do Rio Uruguai (ORICONSUL et al., 2008), trata-se de um conjunto de bacias contíguas de afluentes do rio Uruguai, que ocupam uma área de $8.948,3 \mathrm{~km}^{2}$.

A REBIO de São Donato e sua Zona de Amortecimento fazem parte da sub-região dos rios Butuí-Icamaquã, na Fronteira Oeste do Rio Grande do Sul (RS). A REBIO é uma Unidade de Conservação de proteção integral criada com o Decreto $\mathrm{N}^{\circ} 23.798$, de 12 de março de 1975 pelo governo do estado do RS e possui entorno de 4.392 ha. A sua criação teve como objetivo proteger seu ambiente natural, sendo uma área úmida remanescente, característica do bioma Pampa. 


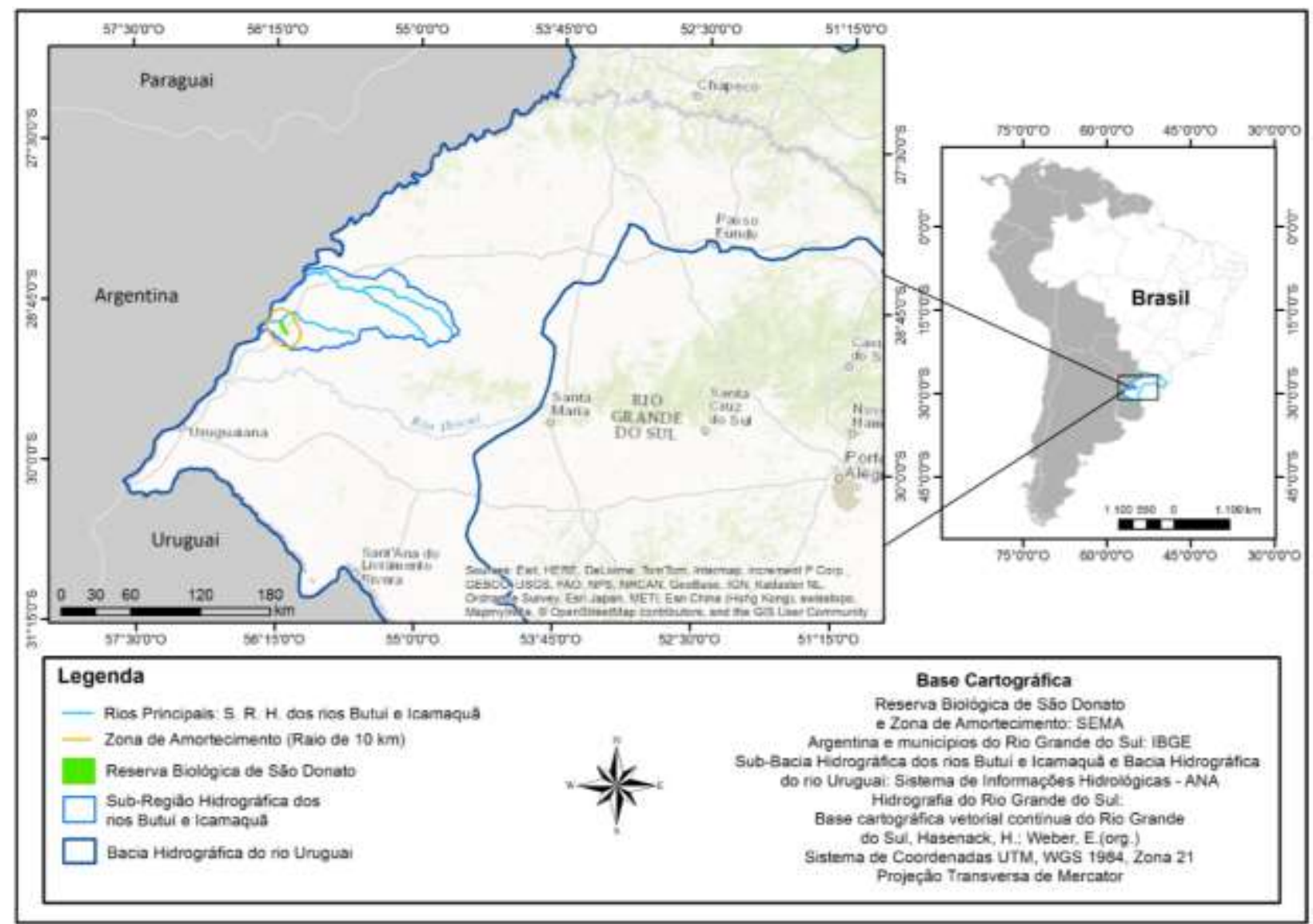

Figura 1: Mapa da sub-região hidrográfica dos rios Butuí-Icamaquã, área da REBIO de São Donato - RS.

Segundo Rossato (2011), o clima subtropical da bacia do rio Uruguai tem menor influência de frentes polares e maiores atuações de frentes tropicais continentais e marítimas, com influência do relevo (escarpa e vales da borda do Planalto Basáltico) e da continentalidade. Além disso, na área da sub-região hidrográfica dos rios Butuí e Icamaquã chove entre 1700 e 1900 mm ao ano, conforme Figura 2, em 100-140 dias de chuva (entre 9 e 12 dias ao mês, podendo ser menos em meses de inverno).

\section{MATERIAIS E MÉTODOS}

Foram obtidos dados pluviométricos do período de 1989, 1990, 2011 e 2016: (a) Estação Pluviométrica da Fazenda Santa Cecília do Butuí (EPButuí), da Agência Nacional de Águas (ANA), localizada na sub-região hidrográfica dos rios Icamaquã e Butuí, coordenadas UTM -28.989698 Sul e -55.674208 Oeste, de 1984 a 2016; (b) a montante, região norte do estado, na área de influência das inundações da bacia do rio Uruguai, na Estação Pluviométrica de Palmitos (EPPalmitos), da Agência Nacional de Águas (ANA), no trecho do alto Uruguai em Santa Catarina, coordenadas UTM -27.064522 Sul e -53.156698 Oeste; (c) Estação Pluviométrica Esquina Araujo (EPEsquina Araujo), da Agência Nacional de Águas (ANA), localizada no município de Independência, no trecho alto da bacia do rio Uruguai, coordenadas UTM -27.969070 Sul e -54.125189 Oeste; e (d) Estação Pluviométrica de Garruchos (EPGarruchos), da Agência Nacional de Águas (ANA), localizada na fronteira com a Argentina, no trecho médio da bacia do rio Uruguai, coordenadas UTM -28.187973 Sul e 55.637329 Oeste (Figura 3).

As datas de imagens foram selecionadas tendo como critério: (a) períodos com totais de precipitação mais altos na sub-região hidrográfica dos rios Butuí-Icamaquã. Segundo Oriconsul et al. (2008), ocorrem no outono e no inverno; e (b) a disponibilidade das imagens no Catálogo de Imagens do Instituto Nacional de Pesquisas Espaciais (INPE). Foram selecionadas as seguintes datas: 18/09/1989, 30/04/1990, 24/04/2011 e 24/06/2016. 


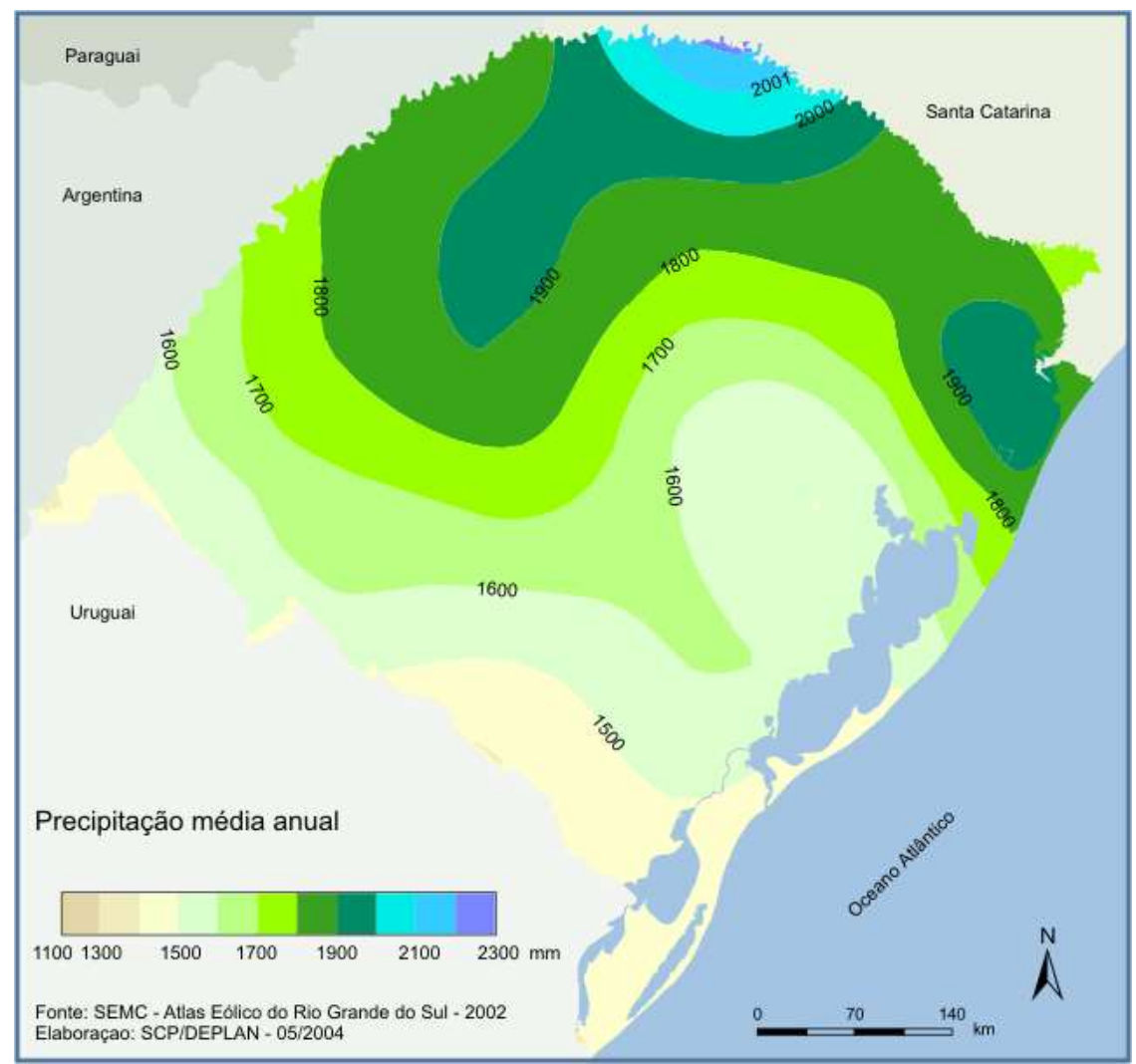

Figura 2: Mapa de Precipitação Média Anual do Rio Grande do Sul. Fonte: Atlas Socioeconômico do Rio Grande do Sul (2014).

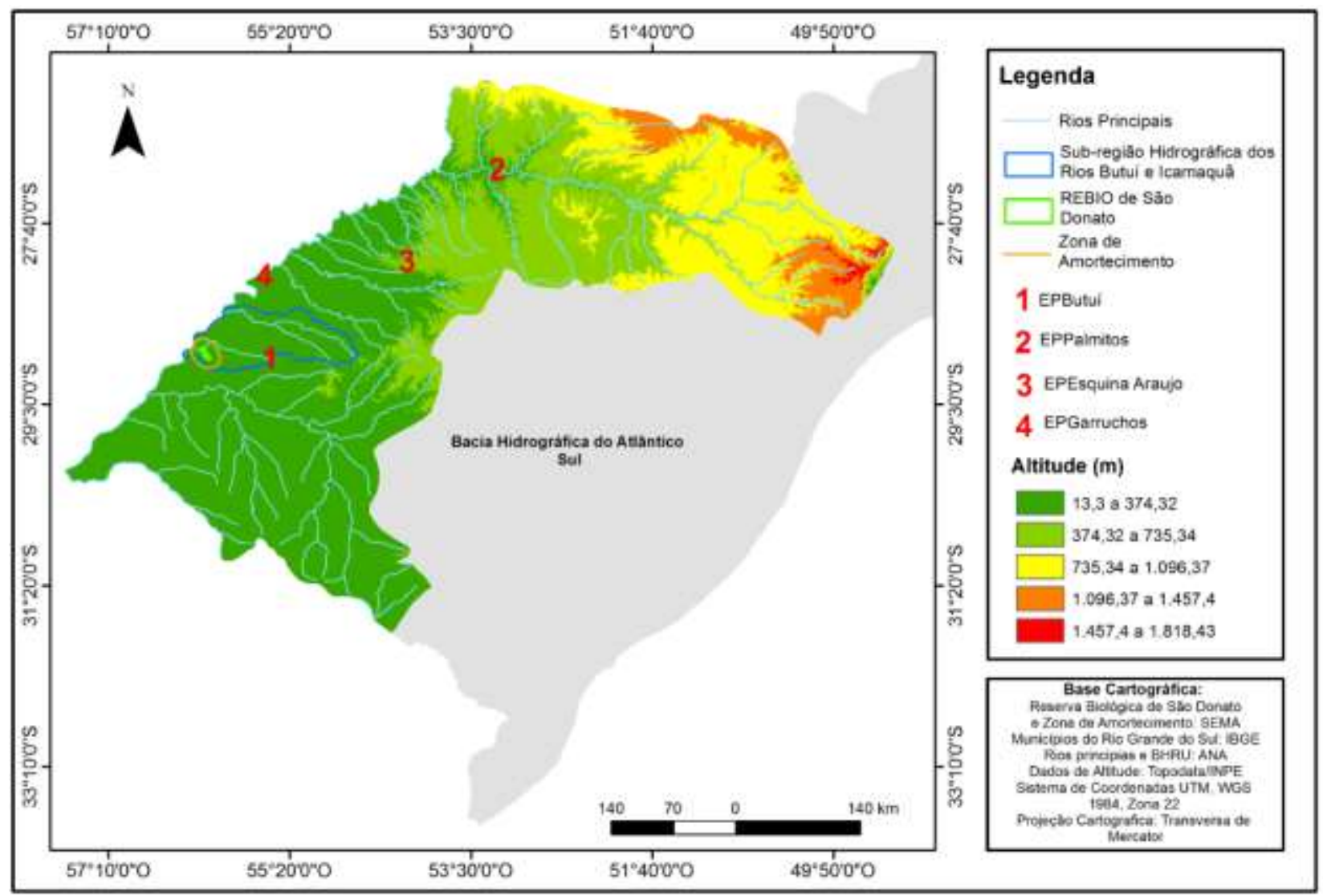

Figura 3: Mapa altimétrico e de localização das estações pluviométricas na Bacia Hidrográfica do Rio Uruguai, RS. 
Para definir um limiar da precipitação para ocorrência de inundação, utilizou-se Righi e Robaina (2010) que definiram um padrão de precipitação relacionado a ocorrência de inundações, utilizando valores diários de precipitação relativos a todas as sub-bacias, obtendo-se um padrão a partir de 50,1 $\mathrm{mm}$ para a ocorrência de inundações. Entretanto, as precipitações consecutivas de 40 a $50,1 \mathrm{~mm}$, também podem influenciar na ocorrência de inundações, conforme classes de intensidade de precipitação Quadro 1.

Quadro 1: Classificação de intensidade das precipitações, conforme registros diários.

\begin{tabular}{|c|c|l|}
\hline Classes & $\begin{array}{c}\text { Precipitação } \\
(\mathbf{m m})\end{array}$ & \multicolumn{1}{c|}{ Caracterização } \\
\hline 1 & $2-10$ & $\begin{array}{l}\text { Possuem os menores índices de chuva, sendo praticamente toda a água } \\
\text { interceptada e armazenada pela vegetação e devolvida à atmosfera por } \\
\text { evaporação. }\end{array}$ \\
\hline 2 & $10,1-50$ & $\begin{array}{l}\text { Caracterizadas como chuvas intermediárias, sendo responsáveis pela } \\
\text { recarga dos mananciais a partir da água de infiltração. }\end{array}$ \\
\hline 3 & $50,1-100$ & $\begin{array}{l}\text { Chuvas de baixa frequência e alta intensidade, potencializa-dores de } \\
\text { desastres naturais e que pouco contribuem para a manutenção da } \\
\text { estabilidade hidrológica do geoecossistema, uma vez que o volume de } \\
\text { água produzido é rapidamente perdido pelo sistema na forma de } \\
\text { escoamento superficial e subsuperficial. }\end{array}$ \\
\hline 4 & $>100$ & \\
\hline
\end{tabular}

Fonte: Adaptado de Righi e Robaina (2010).

As imagens selecionadas foram recortadas a partir da máscara do limite da sub-bacia dos rios ButuíIcamaquã, e utilizadas para a aplicação da equação de bandas do índice NDPI (Normalised Difference Pond Index), Equação 1.

$$
N D P I=\frac{\left(\rho_{\text {swir }}-\rho_{\text {green }}\right)}{\left(\rho_{\text {swir }} \rho_{\text {green }}\right)}
$$

Em que: $\rho_{\text {swir }}$ é a banda do infravermelho distante; $\rho$ green é a banda verde do visível.

De acordo com Lacaux et al. (2007) os valores de NDPI variam de -1 a 1 . Os valores próximos a 1 são relacionados aos corpos de água ou solos inundados, e os próximos a -1 representam áreas mais secas, e com menos umidade na vegetação.

Os valores resultantes do NDPI, para cada imagem, foram reclassificados no software Idrisi Selva buscando destacar os corpos de água e as áreas inundadas. Foram estabelecidas as seguintes classes: Muito Seco (-1 a $0,05)$, Seco $(0,05$ a 0,2$)$, Úmido $(0,2$ a 0,5$)$ e Muito Úmido ( 0,5 a 1$)$, e calculadas a área de cada classe NDPI. A partir das imagens utilizadas para a aplicação do NDPI, foram realizadas composições coloridas (RGB), no software Idrisi Selva, que foram utilizadas para avaliar a relação entre as imagens de NDPI e os dados de precipitação diários.

\section{RESULTADOS E DISCUSSÕES}

De acordo com os dados de precipitação diária, na Figura 4A), que corresponde a imagem de 18/09/1989, nos dias 12, 13 e 14 ocorreram picos de precipitação (classe 3), com respectivamente, na EPEsquina Araujo (92.4 mm), na EPGarruchos (52,8 mm) e na EPPalmitos $(62,1 \mathrm{~mm})$. 

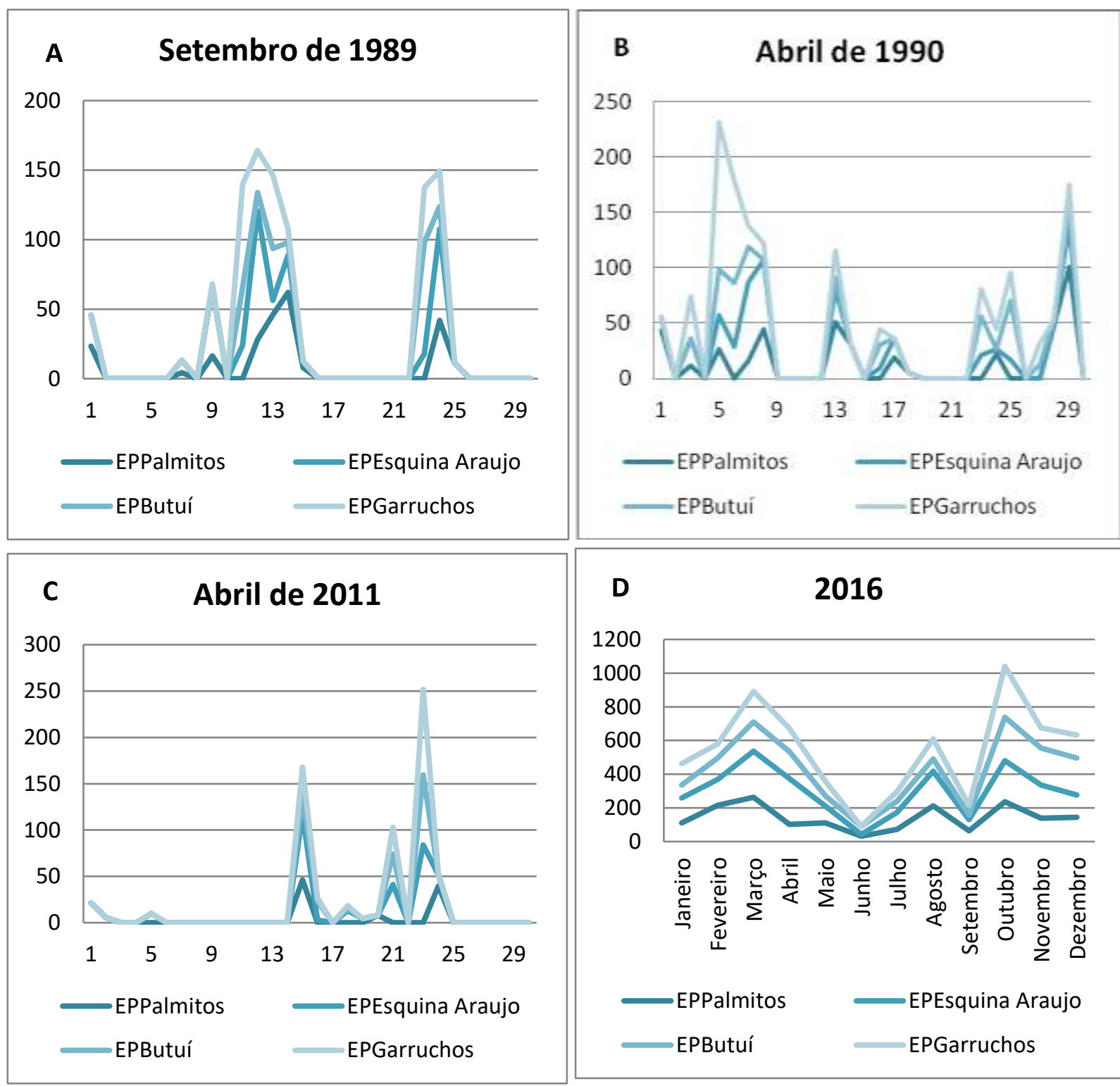

Figura 4: Dados de precipitação diária: (A) setembro de 1989; (B) abril de 1990; (C) abril de 2011. Dados de Precipitação mensal: (D) Médias mensais em 2016.

Para o mês de abril de 1990, Figura 4B, referente a imagem do dia 30/04/1990, nos dias 5, 6, 7, $8,13,25$ e 29 ocorreram picos de precipitação (classe 3), com respectivamente, na EPGarruchos (133,4 mm, no dia 5), na EPButuí (56,8 mm) e na EPGarruchos (92,5 mm, no dia 6), na EPEsquina Araujo (70,6 mm, no dia 7), na EPEsquina Araujo (62,2 mm, no dia 8), na EPPalmitos (51,1 mm, no dia 13), na EPButuí (53,4 mm, dia 25) e na EPPalmitos (101,2 mm, no dia 29). No mês de abril de 2011, Figura 4C, no dia 15 ocorreu pico de precipitação (classe 3) com 71,44 mm e no dia 23 ocorreu pico de precipitação (classe 3), na EPButuí (75,6 mm) e na EPGarruchos (92,2 mm).

No gráfico da Figura 4D, de médias mensais em 2016, os meses de março, abril e outubro tiveram as maiores médias mensais de precipitação, de acordo com a EPButuí, com respectivamente, 172,8 $\mathrm{mm}, 160,6 \mathrm{~mm}$ e 257,2 $\mathrm{mm}$. Nos registros de precipitação da EPPalmitos, março, agosto e outubro foram os meses com maiores médias mensais, com respectivamente, 262,8 mm, 212,8 mm e 235,8 mm. Já na EPEsquina Araujo, março, abril e outubro foram os meses com maiores médias mensais, com respectivamente, $273,8 \mathrm{~mm}, 272,2 \mathrm{~mm}$ e $257,2 \mathrm{~mm}$. E na EPGarruchos, março e outubro foram os meses com maiores médias mensais, com respectivamente, 182,9 mm e 302,7 mm. 
Segundo Binda et al. (2012), a montante no rio Uruguai - na região da EPPalmitos - ocorreram 13 eventos de inundações no mês de março entre os anos de 1980 a 2010. E na região da EPButuí não houve registros de inundação, segundo Righi (2010) e Saueressig (2012).

Já no mês de outubro, ambas as estações registraram eventos de inundação, segundo Binda et al. (2012) foram registradas 31 ocorrências de inundação no período de 1980 a 2010 na área à montante do rio Uruguai, e segundo Saueressig (2012) e Righi (2010) foram identificados 7 eventos de inundação na região do rio Butuí. Além disso, na região da EPEsquina de Araújo, próximo ao município de Santa Rosa, não houve registros de inundação, segundo Righi (2010) e Saueressig (2012). Entretanto, no município de Garruchos, na EPGarruchos, foram registrados dois eventos de inundação entre 1997 e 1998, uma no mês de outubro e outra no mês de abril (RIGHI, 2010).

Segundo os registros de eventos de inundações (RIGHI, 2010; RIGHI e ROBAINA, 2010; BINDA et al., 2012; SAUERESSIG, 2012; RIGHI, 2016), as precipitações na bacia do rio Uruguai não ocorrem de forma similar em todas as sub-regiões da bacia. Além disso, conforme a Figura 5, dos eventos de inundação entre 1980 e 2005 , nota-se que não existe um padrão sazonal para ocorrência de inundações, todavia, os meses de maio (35), outubro (38) e setembro (40) são os meses que mais registraram eventos extremos de inundação.

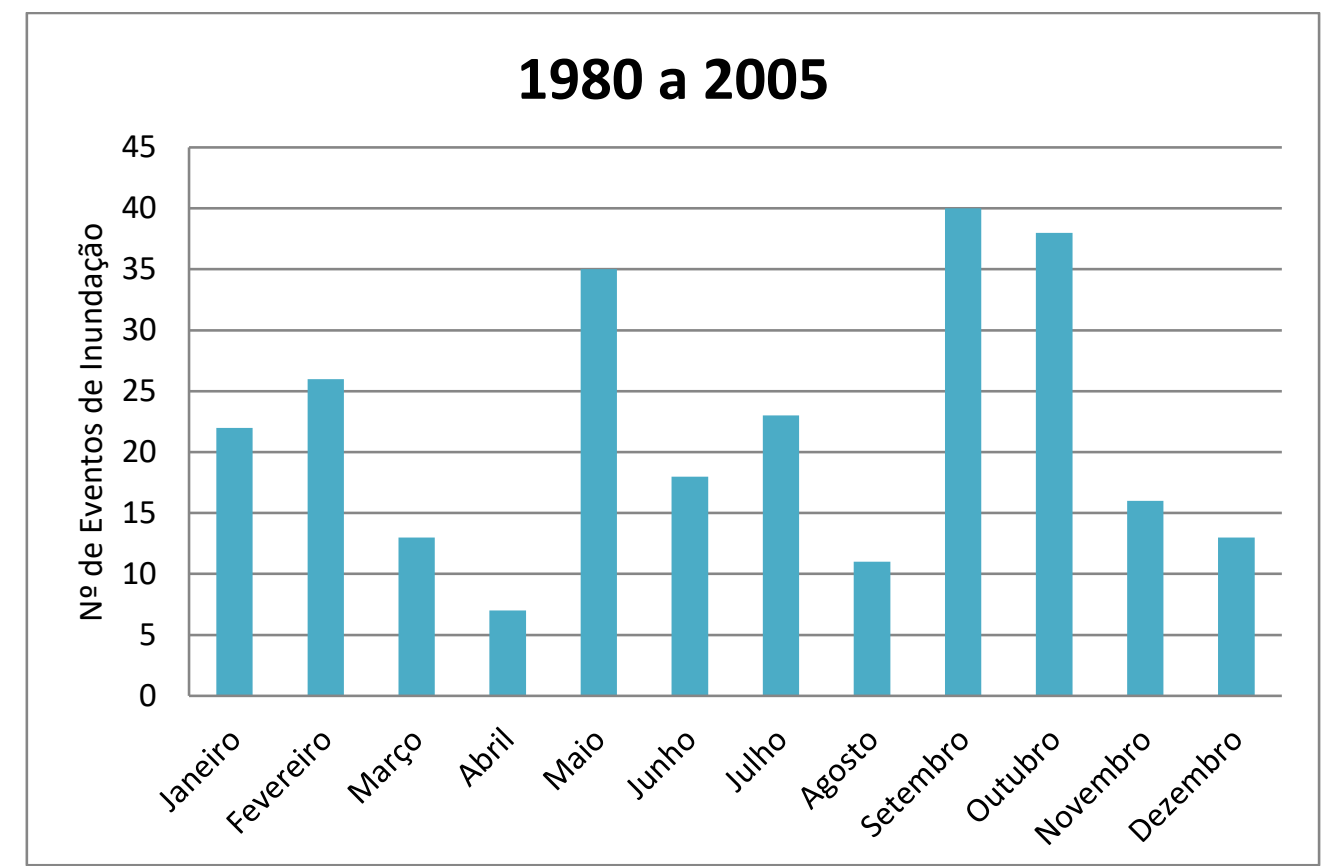

Figura 5: Distribuição mensal dos eventos de inundação na Bacia do Rio Uruguai, entre 1980 e 2005. Fonte: Adapatado de Binda et al. (2012), Saueressig (2012) e Righi (2010).

Conforme Righi e Robaina (2010) picos de precipitação a montante da REBIO favorecem o fluxo acumulado a jusante do rio Uruguai. É importante destacar que a elevação do nível do rio Uruguai exerce influência no represamento do escoamento dos rios Icamaquã e Butuí, elevando o nível dos mesmos.

A Figura 6A evidencia que nessas condições, parte da área do banhado da REBIO de São Donato é inundada, representado por altos valores de NDPI 0,5 a 1. Essa imagem relativa à 18/09/1989, possui o maior registro de área com a classe "muito úmida". Conforme Ray et al. (2012) o NDPI auxilia na identificação de alvos como os corpos de água. A soma da área do banhado inundado com as áreas inundadas dos rios principais totaliza $302,53 \mathrm{~km}^{2}$, Tabela 1 . E chega a $496,55 \mathrm{~km}^{2}$, quando somadas as áreas inundadas e os corpos de água. Esta inundação teve uma abrangência regional, de acordo com os dados de precipitação diários da Figura 4A, a precipitação acumulada ocorreu a montante do rio Uruguai, influenciando várias sub-bacias da bacia do rio Uruguai. Segundo Suertegaray e Moura (2012), os processos erosivos dos rios, contribuem para o aumento de áreas de 
planícies. O assoreamento dos cursos d'água decorrentes da erosão aumenta os limites dessas áreas inundáveis.

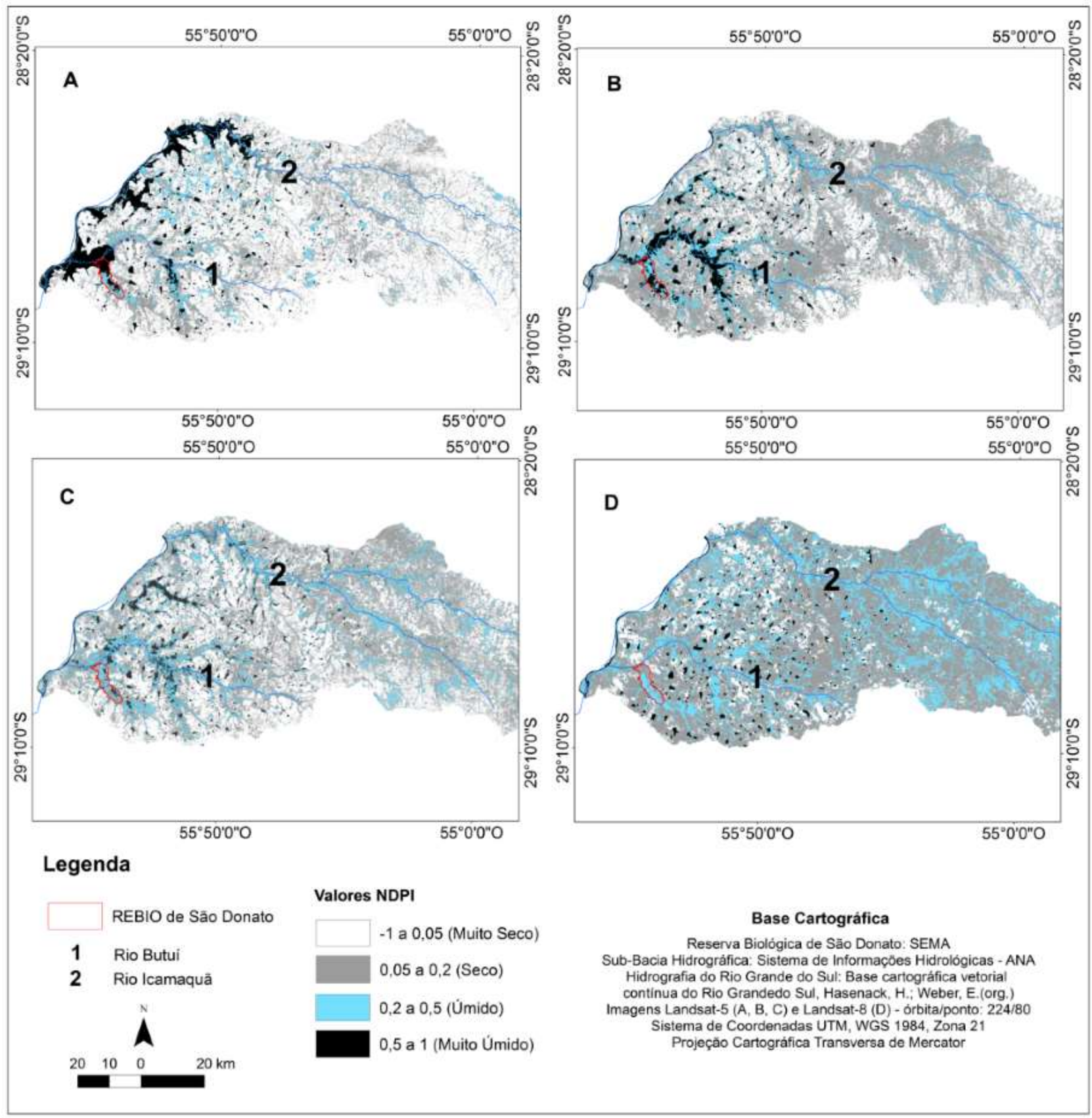

Figura 6: Mapa de classes de NDPI, sub-região hidrográfica dos rios Butuí e Icamaquã: (A) 18/09/1989, (B) 30/04/1990, (C) 24/04/2011 e (D) 24/06/2016.

Segundo Kumar (2015) quando as áreas úmidas possuem uma cobertura de vegetação relativamente mais densa, podem ser influenciadas por esta, sendo caracterizadas por maiores valores de reflectância na banda verde e na banda do infravermelho distante, utilizadas na operação do NDPI. O que pode dificultar a determinação das áreas totais da classe "muito úmido".

Segundo Righi (2011) no mês de abril de 1990 foi registrado um evento de inundação no município de São Borja. Esse evento afetou diretamente o rio Butuí e o banhado da REBIO de São Donato, Figura 6B. A mancha da classe "Muito Úmido", com valores de NDPI de 0,5 a 1, abrange os corpos de água e as áreas inundadas do rio Butuí e do banhado, com um total de $370,9 \mathrm{~km}^{2}$, Tabela 1. 
Tabela 1: Área das classes de NDPI, a partir de imagens LANDSAT, sub-região hidrográfica dos rios Butuí e Icamaquã - RS.

\begin{tabular}{ccccc}
\hline $\begin{array}{c}\text { Data das imagens } \\
\text { Landsat }\end{array}$ & \multicolumn{3}{c}{ Classes de NDPI (km²) } & \\
\hline & Muito Seco & Seco & Úmido & Muito Úmido \\
\hline $18 / 09 / 1989$ & 5074,10 & 1956,46 & 498,35 & 496,55 \\
\hline $30 / 04 / 1990$ & 5022,17 & 3764,53 & 938,47 & 370,90 \\
\hline $24 / 04 / 2011$ & 3617,84 & 4904,33 & 1056,42 & 351,82 \\
\hline $24 / 06 / 2016$ & 1080,00 & 4652,80 & 5816,33 & 205,25 \\
\hline
\end{tabular}

A ocorrência de precipitações diárias de classe 2 e 3 relativas a abril de 1990 tiveram uma abrangência sub-regional, o que influenciou no interior da sub-região hidrográfica dos rios Butuí e Icamaquã, como é observado na Figura 6B.

Na imagem da Figura 6C não há mancha de inundação. Mas a imagem mostra que há bastante umidade no solo, na área do banhado há forte influência da resposta da lâmina de água. Observa-se que a classe "Muito Úmido" tem uma área de $351,82 \mathrm{~km}^{2}$, mas a classe predominante é a "Seca", com $4652,8 \mathrm{~km}^{2}$, Tabela 1. Destaca-se que nessa data que a influência da precipitação ocorreu no trecho baixo da bacia do rio Uruguai, afetando apenas o rio Butuí e seu entorno.

A partir da imagem de NDPI da Figura 6D, apesar de representar uma data referente a um mês com poucas chuvas, é possível observar as áreas úmidas e planícies inundáveis, representadas pela classe "úmida" (valores NDPI de 0,2 a 0,5), sendo a classe predominante, com 5816,33 $\mathrm{km}^{2}$ (Tabela 1).

Segundo Mozumder et al. (2014) e Kumar (2015) o NDPI é adequado para extrair áreas de corpos de água e áreas inundadas. Entretanto, conforme os autores, a aplicação de um único índice não consegue identificar e classificar os diferentes compartimentos de áreas úmidas, devido as contribuições na resposta espectral do solo, vegetação e água nesse sistema. Assim, utilizam também outros índices (NDWI, MNDWI e NDVI) para realizar uma composição dos mesmos com o objetivo de classificar áreas úmidas, diferenciando áreas que possuem vegetação densa ou cobertura de macrófitas.

É possível identificar que as inundações podem se estabelecer com base num padrão regional, como a inundação da Figura 7A, de data 18/09/1989, influenciando não só a área da REBIO, como também, grande parte do trecho médio e alto da bacia do rio Uruguai. A precipitação diária de classe 3, verificada pelos dias 12/09/1989, 13/09/1989 e 14/09/1989, e as precipitações intermediárias consecutivas, de classe 2, contribuíram para as inundações a jusante do rio Uruguai e seus afluentes (Butuí e Icamaquã) e a saturação do solo do banhado da REBIO de São Donato.

Conforme a Figura 7B, de data 30/04/1990, é notável que a inundação afeta uma área subregional. Segundo as ocorrências das precipitações diárias altas e intermediárias consecutivas próximas a montante do rio Butuí, proporcionaram o escoamento à jusante do mesmo e a saturação do solo do banhado da REBIO de São Donato.

Já a Figura 7C, de data 24/04/2011, mostra um padrão local, que compreende apenas a área do banhado da REBIO de São Donato. Nota-se que não se constatam eventos de inundação, apesar da ocorrência de precipitação de classe alta no dia anterior da data da imagem, pois o volume de água não foi suficiente para a ocorrência de inundação. Entretanto, contrastando os eventos de inundação ou de alta umidade na área de estudo, a Figura 7D, de data 24/06/2016, demonstra o banhado da REBIO de São Donato em um período mensal de baixa precipitação, pois é visível que as áreas de planícies de inundação dos rios e a área do banhado não apresentam influência da reflectância da água. 


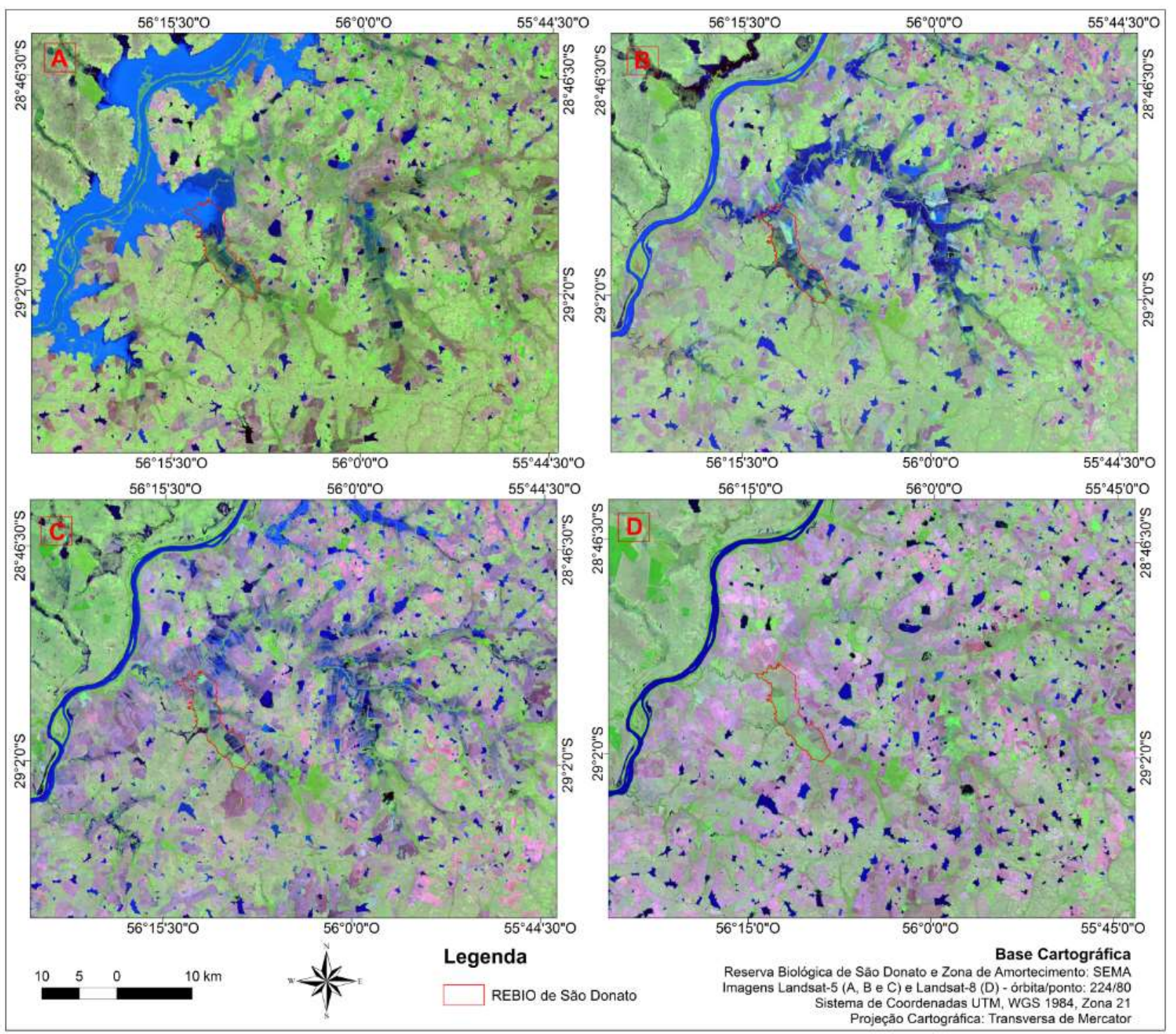

Figura 7: Imagens Landsat TM da área do banhado da REBIO de São Donato: (A) 18/09/1989, (B) 30/04/1990, (C) 24/04/2011 e (D) 24/06/2016.

\section{CONCLUSÕES}

A aplicação do NDPI apresentou bons resultados para identificação das áreas inundadas e corpos de água, facilitando a distinção das classes de Muito Seco, Seco, Úmido e Muito Úmido. Sendo uma importante ferramenta para a definição de padrões de inundação na área da REBIO São Donato.

Foram identificados três padrões de inundação do banhado da REBIO de São Donato, no seu contexto hidrológico e geomorfológico, relacionados aos registros de precipitação diários e mensais e da análise das imagens de NDPI. O primeiro é um padrão regional, que afeta grande parte do trecho médio e alto da bacia do rio Uruguai. O segundo padrão de inundação é sub-regional, compreendendo a sub-região hidrográfica dos rios Butuí-Icamaquã. O terceiro padrão afeta uma área local, compreendendo o banhado da REBIO de São Donato, porém não se constata como evento de inundação.

\section{REFERÊNCIAS}

BINDA, A. L.; BUFFON, E. A. M.; FRITZEN, M. Análise Espaço-Temporal dos Casos de Inundações e de Alagamentos Registrados na Cidade de Chapecó-SC (1980-2010). Revista RAEGA: O Espaço Geográfico em Análise, Curitiba, v. 26, p. 35-50, 2012.

BORGES, R. de O.; CAMARGO, F. F.; CAMPAGNOLI, F.; BAYER, M. Aplicação do Índice de 
Diferença Normalizada da Água (NDWI) na Delimitação de Fluxos de Sedimentos em suspensão no Rio Araguaia: avaliação das imagens Landsat-8 para o monitoramento hidroviário. In: SIMPÓSIO BRASILEIRO DE SENSORIAMENTO REMOTO, 17.; 2015, João Pessoa. Anais... João Pessoa: INPE, 2015. p. 6022-6029.

BRENNER, V. C. Proposta metodológica para renaturalização de trecho retificado do rio Gravataí - RS. 2016. 94 f. Dissertação (Mestrado) - Programa de Pós-Graduação em Geografia, Universidade Federal do Rio Grande do Sul, Porto Alegre, 2016. Disponível em: < http://www.lume.ufrgs.br/handle/10183/142181>. Acesso em: 28 jul. 2017.

BRINSON, M. M. A Hydrogeomorphic Classifications for Wetlands. U. S. Army Corps of Engineers, Washington, v. 1, p. 103, 1993.

BRUBACHER, J. P.; GUASSELLI, L. A. Mapeamento da Área Inundável da Planície do Rio dos Sinos a partir do Índice NDWI, São Leopoldo - RS. In: SIMPÓSIO BRASILEIRO DE SENSORIAMENTO REMOTO, 16; 2013, Foz do Iguaçu. Anais... Foz do Iguaçu: INPE, 2013. p. 4540-4547.

EMBRAPA. Sistema Brasileiro de Classificação de Solos. $2^{\mathrm{a}}$ edição. Rio de Janeiro: EMBRAPA, 2006. 286p.

FEITOSA, J. R. P.; FILHO, J. F. C.; SILVA, B. B. da. Avaliação de Índices de Vegetação em área irrigada do Sub-Médio São Francisco, Petrolina-PE, a partir de imagens do satélite LANDSAT-5, TM. In: CONGRESSO BRASILEIRO DE METEOROLOGIA, 4; 2006, Florianópolis. Anais... Florianópolis: CBMET, 2006. p. 1-11.

GITELSON, A. A.; KAUFMAN, Y. J.; MERZLYAK, M. N. Use of a green channel in remote sensing of global vegetation from EOS-MODIS. Remote Sensing of Environment, v.58, p.289-298, 1996.

INAU. Definição e Classificação das Áreas Úmidas (AUs) Brasileiras: Base Científica para uma Nova Política de Proteção e Manejo Sustentável. INAU, Cuiabá, 2014. Disponível em: $<$ http://www.inau.org.br/documentos/?DocumentosCategoriaCod=\&DocumentosCod=12>. Acesso em: 07 dez. 2016.

IRGA. Safras. IRGA, Porto Alegre, 2015. Disponível em: <http://www.irga.rs.gov.br/conteudo/4215/safras>. Acesso em: 24 dez. 2015.

JI, L.; ZHANG, L.; WYLIE, B. Analysis of Dynamic Thresholds for the Normalized Difference Water Index. Photogrammetric Engineering and Remote Sensing, v. 75, n. 11 p. 1307-1317, 2009.

KOBYIAMA, M.; MENDONÇA M.; MORENO, D. A.; MARCELINO, I. P. V. de O.; MARCELINO, E. V.; GONÇALVES, E. F.; BRAZETTI, L. L. P.; GOERL, R. F.; MOLLERI, G. S. F; RUDORFF, F. de M. Prevenção de Desastres Naturais: conceitos básicos. Curitiba: Ed. Organic Trading, 2006. 109 p.

KUMAR, M. C. V. S. S. Automatic extraction of water features at multiple scales. Dehradun: Master of Technology in Remote Sensing and GIS, Indian Institute of Remote Sensing, 2015. 92 p.

LACAUX, J.P.; TOURRE, Y. M.; VIGNOLLES, C.; NDIONE, J. A.; LAFAYE, M. Classification of ponds from high-spatial resolution remote sensing: Application to Rift Valley Fever epidemics in Senegal. Remote Sensing of Environment, v.1, n. 106 p. 66-74, 2007.

MENESES, P. R.; ALMEIDA, T. Introdução ao Processamento de Imagens de Sensoriamento Remoto. Brasília: UNB, 2012. 276 p.

MOZUMDER, C.; TRIPATHI, N. K.; TIPDECHO, T. Ecosystem evaluation (1989-2012) of Ramsar wetland Deepor Beel using satellite-derived indexes. Environmental Monitoring and Assessment, v.186, n. 11 p.7909-7927, 2014. 
NOVO, E. M. L. M. Sensoriamento Remoto: Princípios e Aplicações. $4^{a}$ edição. São Paulo: Blucher, 2010. 387p.

ORICONSUL; ECOPLAN; SKILL. Plano de Desenvolvimento Sustentável da Região da Bacia do Rio Uruguai. Porto Alegre e Florianópolis: Relatório Final, 2008. 555 p.

RAY, R.; MANDAL, S.; DHARA A. Characterization and Mapping of Inland Wetland: A Case Study on Selected Bils on Nadia District. International Journal of Scientific and Research Publications, v. 2, n. 12 p. 1-10, 2012.

PONZONI, F. J.; SHIMABUKURO, Y. E.; KUPLICH, T. M. Sensoriamento Remoto da vegetação. $2^{\text {a }}$. Ed. Atualizada e ampliada. São Paulo: Oficina de Textos, 2012. 176 p.

RIGHI, E. Risco a Inundação em Médio Curso do Rio Uruguai: Um estudo de caso nos municípios de Porto Lucena e São Borja. 2012. 222f. Dissertação (Mestrado) - Programa de Pós-Graduação em Geografia, Universidade Federal do Rio Grande do Sul, Porto Alegre, 2012. Disponível em: 〈http://www.lume.ufrgs.br/handle/10183/32566>. Acesso em: 28 jul. 2017.

RIGHI, E.; ROBAINA, L. E. de S. Enchentes do Rio Uruguai no Rio Grande do Sul entre 1980 e 2005: Uma Análise Geográfica. Sociedade e Natureza, Uberlândia, v.1, n.22 p.35-54, 2010.

RISSO, J.; RIZZI, R.; RUDORFF, B. F. T; ADAMI, M.; SHIMABUKURO, Y. E.; FORMAGGIO, A. R.; EPIPHANIO, R. D. V. Índices de vegetação Modis aplicados na discriminação de áreas de soja. Pesq. Agropec. Bras., Brasília, v.47, n.9 p.1317-1326, 2012.

ROSSATO, M. S. Os Climas do Rio Grande do Sul: Variabilidade, Tendências e Tipologia. 2011. 253f. Tese (Doutorado) - Programa de Pós-Graduação em Geografia, Universidade Federal do Rio Grande do Sul, Porto Alegre, 2011. Disponível em:< http://www.lume.ufrgs.br/handle/10183/32620>. Acesso em: 27 jul. 2017.

SAAVEDRA, O. F. C.; MUÑOZ, V. A.; REIS, J. B. C. Delimitação da planície inundável e avaliação a partir de um evento de inundação ocorrido no município de São Borja (RS). In: SIMPÓSIO BRASILEIRO DE SENSORIAMENTO REMOTO, 17.; 2015, João Pessoa. Anais... João Pessoa: INPE, 2015. p. 6290-6297.

SAUERESSIG, S. R. Zoneamento das Áreas de Risco a Inundação da Área Urbana de ItaquiRS. 2012. 101f. Dissertação (Mestrado) - Programa de Pós-Graduação em Geografia e Geociências, Universidade Federal de Santa Maria, Santa Maria, 2012. Disponível em:< http://w3.ufsm.br/ppggeo/images/dissertacoes/dissertacoes_2012/Silene\%20Raquel\%20Saueress ig\%20-\%20dissertao.pdf >. Acesso em: 28 jul. 2017.

SECRETARIA DE PLANEJAMENTO, GOVERNANÇA E GESTÃO DO RS. Atlas Socioeconômico do Rio Grande do Sul: Clima, Temperatura e Precipitação. Governo do Estado do RS, Porto Alegre, 2014. Disponível em: <http://www.atlassocioeconomico.rs.gov.br/climatemperatura-e-precipitacao>. Acesso em: 31 Mai. 2017.

SUERTEGARAY, D. M. A.; MOURA, N. S. V. Rio Grande do Sul: paisagens e territórios em transformação. 2. Ed. Porto Alegre: Editora da UFRGS, 2012. 355 p.

VIANA, J. N. L.; RODRIGUES, L. O. P. F.; RAMOS, T. C. Q. Os Impactos Urbano-Socioambientais no/do Canal da Alameda São Boaventura, no Bairro do Fonseca, Niterói - RJ. In: ENCONTRO NACIONAL DOS GEÓGRAFOS, 16.; 2010, Porto Alegre. Anais... Porto Alegre: AGB, 2010.

WANG, Y.; HUANG, F.; WEI, Y. Water Body Extration from Landsat ETM ${ }^{+}$Image Using MNDWI and K-T Transformation. In: ST INTERNATIONAL CONFERENCE ON GEOINFORMATICS, 21.; 2013, Hong Kong. Anais... Hong Kong: WASET, 2013. 